Produto \& Produção, vol. 11, n. 3, p. 69-86, out. 2010

\title{
Os efeitos da colaboração na transação entre o fornecedor e o supermercado: um estudo exploratório
}

\author{
José Geraldo Vidal Vieira \\ Universidade Federal de São Carlos - Campus Sorocaba \\ jose.vidal@ufv.br
}

\author{
Hugo Tsugunobu Yoshida Yoshizaki \\ Universidade de São Paulo \\ $\underline{\text { hugo@usp.br }}$
}

Leonardo Junqueira Lustosa

PUCRJ

lil@ind.puc-rio.br

Este artigo relata uma pesquisa realizada com objetivo de avaliar o papel da colaboração na melhoria do desempenho logístico e na redução dos custos de transação existentes num elo fornecedor-cliente. A metodologia utilizada foi um estudo de caso realizado durante onze meses em uma das maiores redes de supermercado do Brasil. Extratos de entrevistas realizadas com funcionários dos principais fornecedores da rede foram incorporados com o objetivo de elucidar fatos e nuances de aspectos, por vezes, também referentes a outras grandes redes do ramo. Os resultados indicam que o benefício da colaboração aumenta com o volume e a frequiência de pedidos, assim como com o porte e grau de desenvolvimento da estrutura logística do parceiro. A colaboração contribui para diminuir a incerteza nas negociações e para aumentar a especificidade de ativos. A falta de transparência na comunicação e em procedimentos operacionais logísticos contribui para o aumento de assimetrias na informação.

Palavras-chave: Colaboração, desempenho logístico, custos de transação.

This paper reports a research aimed at assessing the role of collaboration in improving logistical performance and reducing transaction costs in a supplier-customer link. The methodology used was an eleven-month case study in one of the largest supermarket chains in Brazil. Excerpts from interviews with officers of key suppliers of the chain were incorporated in order to elucidate facts and nuances of issues that may also refer to other major chains in the industry. The results indicate that the benefit of cooperation increases with the volume and frequency of orders, as well as with the size and degree of development of the partner's logistic structure. Collaboration reduces the uncertainty in negotiations and increases the specificity of assets. The lack of transparency in the communication and logistic operational procedures contributes to the increase in information asymmetries.

Keywords: Collaboration, logistics performance, transaction costs

\section{Introdução}

Sabe-se que, em uma cadeia de suprimentos, a empresa a jusante no fluxo é a primeira a receber o impacto de uma variação de demanda que se propaga e se amplifica a partir do final da cadeia produzindo o efeito chicote (Lee et al., 1997). Por meio de um processo de colaboração entre os parceiros, é possível reduzir o atraso nessa resposta e, conseqüentemente, os impactos causados pelas flutuações dos estoques, como perda de vendas e queda do nível de serviço. Essas oscilações são freqüentemente analisadas pelas redes de varejo e seus fornecedores, objetivando reduzir os custos logísticos e aumentar a disponibilidade ao consumidor final com o emprego de relações de parcerias.
A colaboração está intimamente relacionada à forma como as empresas compartilham informações, realizam ações conjuntas e intensificam relações interpessoais (Vieira, Yoshizaki e Lee, 2009a, Vieira, Yoshizaki e Lustosa, 2010). Evidentemente, para tal é necessário que haja conhecimento das estratégias, ações e dificuldades do parceiro. Dessa forma, uma análise do nível de colaboração num elo de uma cadeia só se torna viável quando é possível mensurar o nível de desempenho logístico dos agentes e entender como as transações ocorrem no dia a dia.

O problema aqui tratado é a falta de integração entre os participantes da cadeia de abastecimento varejista, 
que tradicionalmente têm gerenciado suas respectivas logísticas de forma individualizada. Essa cadeia é composta por fornecedores (produtores, atacadistas e distribuidores) que abastecem supermercados e consumidores finais. Como conseqüência da falta de integração, pode-se constatar assimetria informacional na cadeia. Esta assimetria aumenta os custos logísticos, de negociação (alinhamento estratégico), de contrato e custos de fluxo de informação; ou seja, aumento dos custos de transação, conforme indica a literatura. Entretanto, a colaboração se dá de formas diversas e tem importância variada em função do contexto considerado (fornecedor, atividade, nível gerencial, organização do fornecedor e do mercado etc.).

O objetivo deste artigo é caracterizar o ambiente de transação entre empresas de variados ramos (fornecedores) e supermercados (seus clientes), apresentar e discutir os efeitos da colaboração, sob a ótica de elementos descritos por Vieira, Yoshizaki e Lee (2009b), no desempenho logístico e nos custos de transação. Como contribuição, traz um caso distinto, tratado de forma qualitativa, com discussão de elementos importantes que permeiam nas transações logísticas entre clientes e fornecedores do varejo. O presente artigo apresenta ainda relatos de profissionais de logística, os quais auxiliam na análise de como a colaboração pode auxiliar no incremento do desempenho logístico e redução de custos associados a transações.

Pesquisas aplicadas no campo da Engenharia de Produção corroboram a importância e a atualidade do tema. Pigatto e Alcântara (2007) avaliaram o relacionamento colaborativo entre fornecedores e supermercados de médio porte, por meio de um levantamento de dados junto a dez varejistas e um fornecedor de cada rede. Vieira e Coutinho (2008) avaliaram o relacionamento logístico entre uma distribuidora e seus fornecedores. Em ambos os trabalhos descrevem-se elementos relevantes da colaboração. Vieira e Coutinho (2008) e Vieira e Machado (2009), na tentativa de agrupar os elementos de colaboração e de desempenho logístico por meio de técnicas de análise multivariada de dados, discutiram quais seriam os mais importantes no relacionamento logístico entre parceiros. Outros trabalhos também dão uma forte contribuição para a discussão do tema, entre eles Vieira, Yoshizaki e Dias (2007), Simatupang e Sridharam (2005) e Conceição e Quintão (2004).

Este texto inicia-se com a revisão da literatura sobre os elementos de colaboração, de desempenho logístico e de custos de transação. Essa revisão teve como base o trabalho de Vieira, Yoshizaki e Lee (2009a). Posteriormente, é apresentada uma revisão sobre a relação entre colaboração e desempenho logístico e a relação entre colaboração e custos de transação. A metodologia contempla o método de pesquisa, onde o estudo foi realizado, a coleta e análise dos dados. A seguir, os resultados são apresentados com a caracterização da amostra, do ambiente de transação entre as empresasobjeto e das relações propostas na revisão de literatura. Por fim, as considerações finais enfatizam os principais resultados encontrados como contribuição da pesquisa, bem como as limitações desta.

\section{Revisão sobre os elementos de colaboração, desempenho logístico e custos de transação}

De forma geral, "Colaboração implica fazer alguma coisa junto com outro e esse é exatamente o seu significado. É o desejo ou a necessidade de criar ou de descobrir algo novo, enquanto pensamos ou trabalhamos com outros, que distingue a ação do comportamento (...)”. “(...) colaboração envolve: (a) diferentes visões e perspectivas; (b) objetivos comuns; (c) definir metas em conjunto; $e(d)$ criar novos valores (...)" (Hargrove, 1998, p.25).

A definição anterior ilustra a dificuldade de dissertar sobre a colaboração, já que envolve palavras inseridas em um contexto comportamental e físico. O contexto comportamental envolve confiança (Anderson e Narus, 1990; Ganesan, 1994; Morgan e Hunt, 1994; Kumar, 1996), reciprocidade (Kumar, Scheer e Steenkamp, 1998), flexibilidade (Heide e John, 1992), interdependência (Ganesan, 1994; Mohr e Spekman, 1994), comprometimento (Morgan e Hunt, 1994), entre outros que agrupam os elementos de colaboração (Pigatto e Alcântara, 2007; Vieira e Coutinho, 2008). O contexto físico envolve ações conjuntas (Heide e John, 1990; Sauvage, 2003) e compartilhamento de dados em geral (como informações estratégicas, custos e incentivos) (Barratt, 2004; Simatupang e Sridharan, 2005).

Colaboração pode estar inserida em diversas áreas de pesquisa: Redes de Empresas (definida como uma rede de negócios entre duas ou mais empresas conectadas por meio de relacionamentos de troca envolvidos em interesse comum), segundo Anderson et al. (1994); Teoria de Relacionamentos Sociais (cuida das relações sociais e psicológicas entre os agentes), segundo Morgan e Hunt (1994); Economia dos Custos de Transação (ECT) (envolve custos de coordenar e monitorar as trocas entre as partes), segundo Williamson (1985); Dependência de Recursos (explicada pelas diferentes formas organizacionais, a partir das necessidades das organizações de recursos de produção, mercado e conhecimento humano, que as empresas se engajam em relações com outras para controlar esses recursos escassos), segundo Pfeffer e Salancik (1978); Teoria dos Contratos (em que as ações dos agentes são regulamentas por normas ou simplesmente compromissos entre as partes), segundo MacNeil (1978); Teoria dos Jogos (em que os parceiros buscam resultados 
tipo "ganha-ganha"), segundo Von Neumann e Morgenstern (1972); e diversas formas de parcerias como joint ventures (Kogut, 1989) e alianças (Gray e Wood, 1991).

Os elementos de desempenho logístico são baseados em Ellram (1990); Lambert (1993); Coyle et al. (2003, pp. 484-491); Simatupang e Sridharan (2005), entre outros. Tais elementos se referem às entregas no tempo, entregas completas, entregas sem erro, entregas freqüentes, disponibilidade de produto, cumprimento da agenda de entrega, cobertura de estoque, pedidos devolvidos, entrega de pedido urgente e entrega de pedido em período de pico de demanda.

Neste artigo, a ECT, por ser uma importante teoria no campo de análise dos relacionamentos entre os parceiros (Klein, Frazier e Roth, 1990), complementa as análises dos custos logísticos presentes na cadeia de abastecimento do varejo. Algumas críticas à abordagem dos custos de transação podem ser encontradas em Griesinger (1990), Langlois (1992), Ghoshal e Moran (1996), Hobbs (1996), Rindfleisch e Heide (1997) e Jones et al. (1997).

Os elementos de custos de transação são basicamente aqueles circunscritos às dimensões da transação (especificidade de ativo, incerteza e freqüência), segundo Williamson (1985).

\subsection{A função da colaboração na melhora do desempenho logístico}

Segundo Simatupang e Sridharan (2002), a colaboração em uma cadeia de suprimento pode ser totalmente usada na identificação e na remoção da inércia organizacional que dificulta o melhor desempenho dos parceiros e o atendimento das necessidades dos consumidores finais. Esta inércia, caracterizada pela assimetria de informação, pela falta de alinhamento de incentivos (custos e benefícios) e pela falta de compartilhamento de informação, contribui para a resistência à mudança e impede o sucesso da colaboração logística entre os participantes (Bowersox, 1990; Santos, 2004). Logo, a colaboração pode prover uma melhora no desempenho logístico e adicionar valor ao consumidor final por meio de redução de custos e melhora nos serviços prestados (Simatupang, Sridharan, 2002; Vieira, Yoshizaki e Dias, 2007).

A colaboração ajuda na diminuição dos custos operacionais, do ciclo de pedido e na melhora o desempenho de toda a cadeia de suprimento (Eisenhardt e Schoonhoven, 1996; Parkhe, 1998). Para Corbett et al. (1999), os maiores benefícios são redução de estoques na cadeia, aumento da fatia de mercado, melhora dos níveis de serviço e da qualidade e curto ciclo de desenvolvimento de produto.

Segundo Sahay (2003), a colaboração tem seu foco nas ações conjuntas de atividades logísticas. Essas ações promovem melhor utilização de equipamentos, troca de informação e compartilhamento de recursos relacionados a transporte e armazenagem (como centro de distribuição). As trocas de informação são realizadas por meio eletrônico e facilita o ressuprimento de produtos (mais agilidade, segurança de dados, menor tempo de conferência, menos erros de cadastro de produtos, entre outros).

A Tabela 1 apresenta algumas pesquisas relevantes que relacionaram colaboração a medidas de desempenho logístico.

Tabela 1 - Pesquisas relevantes que associam colaboração e desempenho logístico.

\begin{tabular}{|c|c|c|}
\hline Autor & Elementos de pesquisa & Conclusões da pesquisa \\
\hline $\begin{array}{c}\text { Daugherty, } \\
\text { Ellinger, Gustin } \\
(1996)\end{array}$ & $\begin{array}{l}\text { Integração e desempenho logístico: } \\
\text { redução de tempo de ciclo, redução } \\
\text { de custos, melhoria de qualidade e } \\
\text { de níveis de serviço, outros. }\end{array}$ & $\begin{array}{l}\text { O desempenho logístico é maior para as empresas que estão } \\
\text { integradas com o seu parceiro e são aquelas que desenvolvem } \\
\text { iniciativas colaborativas entre eles. No geral, empresas maiores } \\
\text { têm melhor desempenho logístico do que as menores. }\end{array}$ \\
\hline $\begin{array}{c}\text { Groves e } \\
\text { Valsamakis } \\
(\mathbf{1 9 9 8 )}\end{array}$ & $\begin{array}{l}\text { Produtos devolvidos, entregas em } \\
\text { tempo e completas, número de } \\
\text { entregas por semana, número de } \\
\text { mudança de agenda de entrega, } \\
\text { outros. }\end{array}$ & $\begin{array}{l}\text { Estatisticamente, a parceria tem efeito positivo na entrega de } \\
\text { pedido em tempo, porém as demais medidas não se mostraram } \\
\text { significativas. O nível tecnológico dos fornecedores têxteis é } \\
\text { relativamente menor quando comparado aos demais. }\end{array}$ \\
\hline $\begin{array}{c}\text { Stank, Keller } \\
\text { e Daugherty } \\
(2001)\end{array}$ & $\begin{array}{l}\text { Colaboração interna, colaboração } \\
\text { externa e desempenho logístico. }\end{array}$ & $\begin{array}{l}\text { Colaboração interna é associada ao alto nível de desempenho } \\
\text { logístico. A colaboração externa influencia a interna e } \\
\text { indiretamente afeta o serviço logístico. O desempenho logístico se } \\
\text { mostrou pouco significante na presença da colaboração externa. }\end{array}$ \\
\hline
\end{tabular}




\author{
Sauvage (2003) \\ Moberg e Speh
(2003)
}

\section{Zanquetto, Fearne e \\ Pizzolato (2003)}

\author{
Claro, Claro, \\ Zylbersztajn \\ (2005)
}

\section{Simatupang e Sridharan} (2005)
Esforço de certificação ISO 9000, troca de informação, controle e planejamento de tempo, duração do relacionamento, procedimentos conjuntos de gerenciamento.

Confiança, comprometimento e questões que envolvem baixo desempenho logístico. Essas questões são determinantes para a eliminação de ações ao parceiro.

Ações individuais e conjuntas, benefícios da parceria (redução de custos e de ativos, melhoria de nível de serviço, etc).

Especificidade de ativo (físico e humano), confiança, ações conjuntas, flexibilidade, desempenho, redes de negócio.

Compartilhamento de informação, sincronização de decisões, alinhamento de incentivos e medidas de desempenho logístico.
O esforço tecnológico entre os parceiros é necessário, mas não suficiente para dar continuidade à parceria. O principal obstáculo é o comportamento. O estudo revela um forte gerenciamento conjunto das atividades logísticas entre clientes e operadores logísticos, com uso cada vez crescente de TI como EDI, por exemplo.

Os varejistas colocam mais questões de retaliação do que os atacadistas. Essas retaliações se elevam à medida que diminui o grau de confiança e de comprometimento entre as partes. Relacionamentos de curto prazo objetivam a redução de custos e investimentos específicos em logística.

A importância da capacidade de inovação (ações conjuntoindividuais) e a habilidade de controle e medida de custos estão associadas à melhoria do nível de serviço. Ações conjuntoindividuais consistem em elemento importante na parceria.

As informações obtidas pelos membros à jusante da cadeia têm maior influência no relacionamento entre fornecedores e varejistas do que outros membros da rede. Logo, a informação de valor está na demanda. Informações obtidas da rede podem reduzir as assimetrias de informação.

As três dimensões de colaboração influenciam positivamente o desempenho no nível de serviço. O alinhamento de incentivos e a sincronização de decisões quando combinadas fortalecem a colaboração e o desempenho logístico.
A Tabela 1 mostra que as pesquisas têm revelado um aumento do desempenho logístico na presença de colaboração. Essa convergência é esperada à medida que os parceiros buscam reduzir o tempo de ciclo de pedido e custos na cadeia (Collins, Henchion e O'Reilly, 2001). A presente pesquisa segue a linha de Simatupang e Sridharan (2005) no sentido de que há uma relação de dependência entre colaboração e desempenho logístico. Na Tabela 1, pode-se notar ainda que são vários os elementos que definem colaboração e desempenho logístico. Uma contribuição da pesquisa é avaliar os elementos já utilizados pela rede varejista do estudo de caso que faz uso deles para avaliar os seus fornecedores.

\subsection{A função da colaboração na redução dos custos de transação}

"Freqüentemente é comum assumir que a colaboração ou outra estrutura relacional reduz os custos de transação e conduz a melhoria do desempenho dos negócios. Mas isto é sempre verdade?" (Corsten e Felde, 2005). Os autores não chegaram a uma clara decisão, apenas concluíram que a colaboração tem um efeito positivo no desempenho financeiro dos parceiros e na capacidade de inovação. Por outro lado, Cannon e Homburg (2001) defendem que a colaboração promove menor custo de contratação (negociação), comunicação mais freqüente e melhora sensivelmente a coordenação de ações conjuntas para resolução de problema diário.
Segundo Day (1995) a colaboração promove um potencial benefício econômico entre as partes e freqüentemente a flexibilidade das parcerias é uma forma de amortecer as turbulências e incertezas do mercado. Para Sahay (2003), o sucesso da colaboração é a freqüência de interação entre os parceiros. Quanto maior a freqüência de contato, maior o comprometimento das partes e menores os custos de transação (Heide e Miner, 1992). Esse fato é corroborado por Vieira, Yoshizaki e Dias (2007), os quais afirmam que custos de negociação e renegociação de acordos logísticos são reduzidos quando as transações de colaboração são recorrentes. Por outro lado, essa interação freqüente pode envolver maior dependência de uma das partes quanto ao investimento em recursos. Logo, pode aumentar o investimento em ativos específicos (físico e humano) e aumentar os custos de transação (Jap e Ganesan, 2000).

Segundo Evans e Wolf (2005), sob certas circunstâncias, a confiança (elemento essencial de colaboração) é um substituto viável para contratos de mercado e de autoridade hierárquica, pois pode atuar no sentido de reduzir custos de negociação e supervisão, ou seja, custos de transação.

Para Nesheim (2001), a interação entre os parceiros permite um alto fluxo de informação que possibilita um efetivo uso de técnicas como análise de valor e engenharia de valor. Isso resulta na redução de custos, no 
compartilhamento de benefícios com a aprendizagem e na confiança para investimentos.
A Tabela 2 apresenta pesquisas relevantes que relacionam colaboração aos custos de transação.

Tabela 2 - Pesquisas relevantes que associam colaboração e custos de transação.

\begin{tabular}{|c|c|c|}
\hline Autor & Elementos de pesquisa & Conclusões da pesquisa \\
\hline $\begin{array}{c}\text { Heide e John } \\
\text { (1990) }\end{array}$ & $\begin{array}{l}\text { Especificidade de ativo, incerteza, } \\
\text { ações conjuntas e continuidade de } \\
\text { relacionamentos. }\end{array}$ & $\begin{array}{c}\text { Ações conjuntas são positivamente relacionadas aos investimentos } \\
\text { específicos. Incerteza e especificidade de ativo são positivamente } \\
\text { relacionadas ao monitoramento da transação. }\end{array}$ \\
\hline $\begin{array}{c}\text { Heide e John } \\
\text { (1992) }\end{array}$ & $\begin{array}{l}\text { Especificidade de ativo, normas } \\
\text { relacionais (flexibilidade, troca de } \\
\text { informação, solidariedade) e integração } \\
\text { vertical. }\end{array}$ & $\begin{array}{l}\text { Investimentos em ativos específicos feitos pelos compradores são } \\
\text { positivamente relacionados ao controle dos fornecedores quando } \\
\text { ambas as partes compartilham as normas relacionais. }\end{array}$ \\
\hline Dyer (1996) & $\begin{array}{l}\text { Especificidade de ativo físico, humano } \\
\text { e de lugar, colaboração e custos de } \\
\text { transação. }\end{array}$ & $\begin{array}{l}\text { Os custos de transação e a especificidade de ativo se mantêm } \\
\text { altos se o ambiente institucional (cultura) se manter constante. } \\
\text { Na cultura japonesa esse ambiente é diferente, pois há pouco } \\
\text { oportunismo dos agentes (Dyer, 1996). }\end{array}$ \\
\hline $\begin{array}{c}\text { Ganesan } \\
(1994)\end{array}$ & $\begin{array}{l}\text { Relacionamento cliente e } \\
\text { fornecedor, especificidade de ativo, } \\
\text { interdependência e incerteza, confiança } \\
\text { e antecedentes. }\end{array}$ & $\begin{array}{l}\text { O investimento em ativo específico cria uma dependência entre as } \\
\text { partes, criando uma barreira de saída da relação. A confiança como } \\
\text { crédito e a interdependência são fatores-chave na orientação de } \\
\text { longo prazo. }\end{array}$ \\
\hline Dyer (1997) & $\begin{array}{l}\text { Compartilhamento de informação, } \\
\text { especificidade de ativo, } \\
\text { comprometimento, reputação, } \\
\text { assimetria de informação custos de } \\
\text { transação, colaboração, etc. }\end{array}$ & $\begin{array}{c}\text { A indústria automobilística japonesa compartilha mais informação } \\
\text { do que a americana e com menos assimetria de informação, o que } \\
\text { permite reduzir os custos de transação. Os custos de transação } \\
\text { na cadeia japonesa são menores e os fornecedores são mais } \\
\text { especializados. }\end{array}$ \\
\hline $\begin{array}{l}\text { Nesheim } \\
(2001)\end{array}$ & $\begin{array}{l}\text { Troca de informação, confiança, } \\
\text { projetos bilaterais e especificidade de } \\
\text { ativo. }\end{array}$ & $\begin{array}{c}\text { Relações colaborativas com fornecedores externos são } \\
\text { positivamente relacionadas com a especificidade de ativo e troca } \\
\text { de informação a ponto de criar valor na transação. As demais } \\
\text { variáveis também se mostraram correlacionadas positivamente } \\
\text { com a colaboração. }\end{array}$ \\
\hline $\begin{array}{l}\text { Cannon e } \\
\text { Homburg } \\
(\mathbf{2 0 0 1 )}\end{array}$ & $\begin{array}{l}\text { Compartilhamento de informação, } \\
\text { comunicação, proximidade geográfica, } \\
\text { flexibilidade, relacionamento } \\
\text { adaptativo, monitoramento. }\end{array}$ & $\begin{array}{l}\text { O aumento da freqüência de comunicação, a proximidade } \\
\text { geográfica, adaptações dos fornecedores e a qualidade dos } \\
\text { produtos facilitam a comercialização com os clientes e reduzem os } \\
\text { custos de transação. }\end{array}$ \\
\hline Batt (2003) & $\begin{array}{l}\text { Relacionamento cliente e fornecedor, } \\
\text { incerteza, satisfação, confiança, } \\
\text { dependência e satisfação. }\end{array}$ & $\begin{array}{l}\text { A maioria dos produtores está satisfeita com os seus parceiros } \\
\text { de mercado e muitos confiam neles. Porém, como há muitos } \\
\text { fornecedores, a incerteza é menor para os relacionamentos de } \\
\text { longo prazo. }\end{array}$ \\
\hline $\begin{array}{c}\text { Know e Suh } \\
\quad(2004)\end{array}$ & $\begin{array}{l}\text { Especificidade de ativo, incerteza, } \\
\text { compartilhamento de informação, } \\
\text { confiança e comprometimento, } \\
\text { satisfação percebida, reputação, } \\
\text { conflito }\end{array}$ & $\begin{array}{c}\text { A confiança entre os parceiros apresentou um impacto } \\
\text { positivo na especificidade de ativo e negativo na incerteza. O } \\
\text { compartilhamento de informação reduz a incerteza e melhora } \\
\text { a confiança. Há um relacionamento circular entre confiança e } \\
\text { especificidade de ativo. }\end{array}$ \\
\hline
\end{tabular}

A Tabela 2 mostra a relação entre elementos de colaboração (como compartilhamento de informação, confiança, flexibilidade, interdependência, entre outros) e as três dimensões da transação (freqüência, incerteza e especificidade de ativo). A maioria das pesquisas converge no sentido de que há um efeito positivo entre a colaboração e a especificidade de ativo e um efeito negativo entre colaboração e incerteza. A presente pesquisa segue a linha de Dyer (1997), que defende que o aumento da colaboração reduz os custos de transação e que o aumento dos custos de transação nem sempre estão associados ao aumento da especificidade de ativo. Segundo o autor, a confiança na relação é forte o suficiente para reduzir salvaguardas. As duas contribuições desta pesquisa em relação à de Dyer (1997) são: a) avaliar elementos diferentes que caracterizam colaboração e custos de transação, e b) avaliar a relação colaboração e desempenho logístico. 


\section{Metodologia}

Este artigo mostra uma análise qualitativa, rica em resultados práticos, a partir de entrevistas, observações e da participação em reuniões com profissionais da área de logística que permitiram identificar como se dá a colaboração logística entre grandes redes varejistas e seus principais fornecedores.

Conforme Yin (1989), dentre os métodos, o estudo de caso é o mais indicado quando se deseja fazer uma investigação para se preservar as características holísticas e significativas dos eventos da vida real, processos organizacionais e administrativos. Neste caso, o estudo permitiu um levantamento e análise profunda de elementos inerentes à transação logística, sobretudo sobre os aspectos de colaboração logística, indicadores de desempenho e custos indiretos oriundos do relacionamento diário entre os parceiros.

Com base nas características do tema de pesquisa, definiu-se o estudo de caso como o método a ser utilizado no desenvolvimento deste trabalho. Lazzarini (1995) ressalta vantagens desse método, sendo relevante para esta pesquisa: (a) proporcionar indicações sobre aspectos ainda não percebidos em pesquisas anteriores feitas em outros ambientes, (b) o fato de "colaboração" ter forte componente comportamental, tornado difícil isolar o fenômeno de seu contexto, e (c) a possibilidade de criar novas linhas de observação à medida que informações as sugerem. Os estudos se desenvolveram in loco e contaram com a participação dos profissionais de logística (analistas, coordenadores, gerentes, supervisores e diretores) diretamente envolvidos nas atividades, permitindo analisar situações diversas e peculiares a cada aspecto logístico do fornecedor.

\subsection{Coleta de dados}

O estudo de caso foi realizado em uma das maiores redes de varejo nacional durante onze meses, com freqüência média de duas visitas por semana. Durante esse tempo, foram acompanhadas reuniões com os profissionais de logística, seminários e fóruns com a participação dos parceiros e reuniões internas à rede varejista, totalizando aproximadamente 250 horas de observações. Ao longo deste acompanhamento, foram realizadas visitas técnicas a fornecedores-chave e observadas as transações de abastecimento ao centro de distribuição da rede varejista pelos seus fornecedores.

Além disso, a rede varejista realizava reuniões mensais para tratar de assuntos logísticos (indicadores de desempenho e novos projetos) como forma de acompanhar a evolução da parceria, o que facilitou o contato direto do entrevistador com os fornecedores para o levantamento de dados.
Os dados coletados por meio do estudo de caso serviram de base para construção do questionário, com pré-teste e desenvolvimento do instrumento final. Este foi aplicado diretamente a 125 profissionais de logística (diretores, gerentes, coordenadores e analistas) de 90 fornecedores de bens de consumo duráveis e não-duráveis.

A aplicação do questionário e as entrevistas com os participantes se deram da seguinte forma: mensalmente o representante do fornecedor fazia reuniões com a rede varejista. Durante estas, eram coletadas informações pertinentes à pesquisa e, ao final, as entrevistas e o preenchimento do questionário eram realizados pelo pesquisador com o representante do fornecedor, sem a presença do parceiro varejista. As entrevistas para coleta desses dados tiveram duração média de uma hora e meia, durante quatro meses. Esses fornecedores estavam entre os principais da rede varejista.

\subsection{O questionário}

O questionário, disponível em Vieira, Yoshizaki e Ho (2009b), está dividido em seis blocos.

\subsubsection{Objetivos de cada bloco}

Bloco 1: é composto por quatro questões (ou variáveis) e tem como objetivo principal caracterizar as empresas fornecedoras participantes e servir como variáveis de controle para as análises estatísticas. As variáveis de controle deste bloco são as seguintes: (a) setor (mercearia-seca, higiene e limpeza, bebidas, commodity, bazar e eletroeletrônico); (b) capital de origem da empresa (variável importante para analisar se há diferença de colaboração entre empresas nacionais e não-nacionais, por exemplo, nos aspectos culturais e organizacionais); (c) localização da empresa (é uma variável que tende a influenciar o desempenho logístico dos fornecedores, pois à medida que aumenta a distância para entrega dos produtos, a complexidade de atender a um pedido perfeito aumenta); (d) número de funcionários (pode, como indicador do porte da empresa, representar o grau de simetria entre as empresas no que se refere ao poder de cada uma nas relações comerciais).

Bloco 2: esse bloco objetiva caracterizar o varejo que seria avaliado pelo entrevistado; como o nome da rede varejista não seria revelado, precisavam-se obter informações para futuras análises. As variáveis associadas são: capital do varejo (nacional e não nacional) e a posição no ranking (montante de vendas).

Bloco 3: esse bloco, composto por seis variáveis, teve o objetivo de permitir a consideração de variáveis indicadoras relevantes na análise das respostas do questionário sobre os temas pesquisados, tais como: 
(a) volume de vendas. Essa variável pode fazer parte não só da análise do desempenho logístico dos fornecedores, pois um maior volume de vendas significa maior volume de entregas, mas também da análise dos custos de transação e da colaboração. Em relação aos custos de transação, um maior volume de vendas pode significar melhores acordos e maior freqüência de pedido, entre outros. Também pode significar maior investimento em algum ativo especializado, maiores problemas com devolução de produtos e maior número de resoluções de contingências logísticas.

Em relação à colaboração, um maior volume de vendas pode significar melhor sinergia na negociação, maior compartilhamento de informações comerciais e maior compartilhamento de custos, pois o aumento da escala pode reduzir os custos entre as partes;

(b) número de SKUs (stock keeping units, ou itens de estoque): segue a mesma lógica da variável anterior, porém está mais associada à área logística. Quanto maior o número de SKUs, maior a dificuldade para cumprir as metas logísticas, pois aumenta a probabilidade de entregas incompletas, com erros e fora da data prometida;

(c) freqüência de entrega: é uma variável que pode ser usada como medida de desempenho logístico. Pode influenciar positivamente a colaboração, pois o aumento da frequiência de entrega aumenta o contato e conhecimento das partes. Além disso, também pode ser usada para avaliar os custos de transação, pois uma maior frequiência reduz o oportunismo ex-post e reduz as incertezas de novas contratações;

(d) prazo de entrega: é uma variável que pode ser usada para medir o ciclo de pedido, servindo para avaliar o desempenho logístico dos parceiros;

(e) freqüência de reuniões logísticas: é uma variável que pode ser usada para demonstrar que a maior frequiência de reuniões aproxima os parceiros e estabelece contatos entre as áreas funcionais das duas empresas;

(f) ocorrência de visitas técnicas: segue a mesma linha da variável anterior. Quanto maior conhecimento do parceiro, melhor o entendimento das suas dificuldades e oportunidades logísticas.

(g) Histórico de relacionamento: refere-se ao tempo de parceria acumulado ao longo dos anos. Tais experiências, em relações anteriores, podem ser tratadas como facilitadoras de colaboração. Entende-se que um bom histórico, ou seja, um bom retrospecto com um determinado parceiro, confirmam sua credibilidade.
Bloco 4: esse bloco contém uma questão (26 variáveis) e teve o objetivo de avaliar o grau de colaboração entre os parceiros;

Bloco 5: composto por uma questão (10 variáveis), este bloco teve o objetivo de avaliar o desempenho do fornecedor em relação ao parceiro.

Bloco 6: composto por uma questão (5 variáveis) teve o objetivo de avaliar os custos de transação decorrentes do relacionamento entre os parceiros.

As variáveis "frequiência de reuniões logísticas" e "ocorrência de visitas técnicas" do bloco 3 foram analisadas detalhadamente por Vieira, Yoshizaki e Ho (2009a). As variáveis dos blocos 4, 5 e 6 foram analisadas por meio de métodos estatísticos multivariados descritos e disponíveis em Vieira, Yoshizaki e Ho (2009a; 2009b). Neste artigo, tais variáveis são analisadas de forma qualitativa por meio de relatos dos entrevistados e de observações tanto na rede varejista como em alguns fornecedores.

\subsection{Análise dos dados}

Os dados do estudo de caso e dos questionários foram analisados qualitativamente, por meio de depoimentos dos respondentes que relataram experiências com o seu parceiro. Esses depoimentos foram interpretados de acordo com a base teórica, procurando verificar os efeitos que a colaboração exerce no desempenho logístico e nos custos de transação presentes no elo. Foram montados quadros comparativos de alguns elementos de colaboração e de custos de transação analisados sob a ótica do fornecedor e do varejista. Os dados do questionário possibilitaram uma análise de freqüência para caracterizar as empresas fornecedoras e o ambiente de transação entre os parceiros. Além disso, procurou-se identificar o nível de colaboração, desempenho logístico e investimentos em ativos dedicados entre os fornecedores e o tipo de varejo (nacional e não-nacional).

\section{Resultados e discussão}

\subsection{Caracterização das empresas (fornecedores)}

As empresas foram divididas em dois grandes grupos: não-alimentos e mercearia. $\mathrm{O}$ grupo de não-alimentos (com 32 participantes) é formado pelos setores bazar e eletro-eletrônico. O grupo mercearia (com 93 participantes) é formado pelos setores commodity, bebidas, mercearia-seca e higiene-e-limpeza (H\&L). Esses grupos seguem a mesma classificação adotada pela rede varejista. 
Como indicador para avaliar o tamanho das empresas, utilizaram-se dois critérios: o número de funcionários (acima ou abaixo de 500) e o faturamento das empresas.
A Tabela 3 mostra, para os grupos mercearia e nãoalimentos, a porcentagem de empresas que se localizam fora/dentro da Grande São Paulo e a porcentagem de empresas que têm maior/menor número de funcionários.

Tabela 3 - Dados geográficos e populacionais das empresas, por grupos setoriais.

\begin{tabular}{c|cc|c}
\hline \multirow{2}{*}{ Grupo } & \multicolumn{2}{|c|}{ Localização da empresa } & Número de funcionários \\
\hline \multirow{2}{*}{ Mercearia } & Fora da Grande São Paulo & Grande São Paulo & Acima de 500 \\
\cline { 2 - 4 } N-alimentos & $40,0 \%$ & $34,4 \%$ & $49,6 \%$ \\
TOTAL & $16,0 \%$ & $9,6 \%$ & $18,4 \%$ \\
\hline
\end{tabular}

Cerca de $44 \%$ dos participantes estão localizados na Grande São Paulo ou têm um centro de distribuição próximo aos grandes mercados consumidores. Em termos de distância absoluta, 55,2\% dos participantes se encontra num raio médio menor que $100 \mathrm{~km}$. O setor eletro-eletrônico está a um raio médio de $3000 \mathrm{~km}$, o que dificulta a entrega dos produtos em tempo. Vale ressaltar que os setores de H\&L e de mercearia-seca representam, juntos, aproximadamente $29 \%$ do total de representantes dentro da Grande São Paulo. Os setores com maior número de produtos estão localizados mais próximos aos centros de distribuição das grandes redes. Já fora da Grande São Paulo, os setores de commodity, bebidas e de eletro-eletrônico são os mais relevantes.

Quanto ao número de funcionários, 68\% representam empresas que têm acima de 500 funcionários. Por outro lado, apenas 9,6\% das empresas com número de funcionários abaixo de 500 são de capital não-nacional, enquanto que $22,4 \%$ são de capital nacional.

A Tabela 4 apresenta quatro faixas de faturamento das empresas.

Tabela 4 - Faturamento anual das empresas por setor.

\begin{tabular}{cc}
\hline Faturamento anual & $\begin{array}{c}\text { \% do número de } \\
\text { empresa }\end{array}$ \\
\hline$<=$ a $\mathrm{R} \$ 15$ milhões & 24 \\
$>\mathrm{R} \$ 15$ mi e $<=\mathrm{R} \$ 480 \mathrm{mi}$ & 24 \\
$>\mathrm{R} \$ 480$ mi e $<1,1$ bilhão & 24 \\
$>=$ a $\mathrm{R} \$ 1,1$ bilhões & 28 \\
\hline
\end{tabular}

As faixas descritas na Tabela 4 foram divididas por meio de quartis. $65 \%$ das empresas têm faturamento acima de R\$480 milhões e, segundo a ABIA (Associação Brasileira das Indústrias da Alimentação), são consideradas empresas de grande porte na cadeia do varejo.

\subsection{Caracterização do ambiente de transação entre os parceiros}

As variáveis que compõem a caracterização do ambiente de transação fornecedor-parceiro varejista estão divididas em três blocos: montante transacionado, que se refere ao volume de vendas do fornecedor e ao número de SKUs, desempenho logístico (prazo de entrega e freqüência de entrega dos produtos) e conhecimento do parceiro (frequiência de reuniões logísticas e ocorrência de visitas técnicas).

\subsubsection{Montante transacionado}

O montante transacionado representa o volume de produtos (em termos de faturamento e quantidade) que o fornecedor vende para o varejista (ou quanto este representa no negócio do fornecedor). Quanto maior o montante transacionado, maior será o envolvimento dos parceiros nos negócios.

A Figura 1 mostra, para cada grupo (mercearia e nãoalimentos), a porcentagem do volume de vendas que o varejista representa no faturamento total do fornecedor. As três faixas de valores (menor que $5 \%$, entre 5 e $10 \%$ e acima de $10 \%$ ) foram divididas com base nas frequiências do volume de vendas. Logo, percebe-se que a maior parte dos fornecedores tem o varejista como um cliente que representa apenas $5 \%$ no seu faturamento.

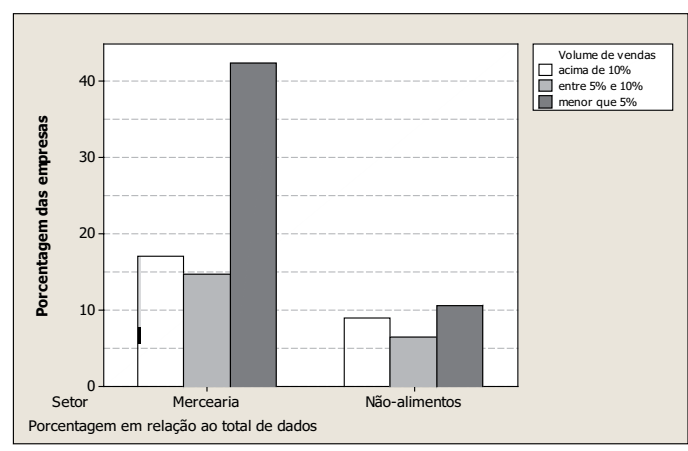

Figura 1 - Volume de vendas do fornecedor para o parceiro: grupo mercearia e não-alimentos. 
Aproximadamente $80 \%$ dos respondentes declararam que o varejista representa até $10 \%$ do faturamento da empresa. Muitos declararam que o grande varejo serve somente como vitrine para os seus produtos e que o maior canal tem sido os atacadistas, principalmente para produtos de H\&L e Seca. Essa informação levou à investigação de quais setores apresentam maior volume de vendas (em percentagem, vide Tabela 4).

Tabela 4 - Volume de vendas que o grande varejo representa para o setor industrial (estatística básica por sub-setor).

\begin{tabular}{cccccc}
\hline Variável & Sub-setores & Média & Desvio padrão & Mediana & 3o Quartil \\
\hline Volume & H\&L & 4,84 & 4,73 & 4,00 & 5,60 \\
De & Eletro-eletr. & 8,74 & 6,66 & 7,00 & 16,00 \\
Vendas & Bazar & 9,12 & 15,00 & 5,00 & 14,50 \\
em \% & Seca & 9,27 & 13,53 & 18,42 & 8,00 \\
& Bebidas & 14,25 & 14,20 & 8,00 \\
\hline \hline
\end{tabular}

Observa-se que o sub-setor de H\&L apresenta menor variabilidade nas medidas centrais (desvio-padrão), é o setor mais representativo na amostra (com número de empresas participantes na pesquisa) e apresenta o menor volume de vendas para o varejista. $75 \%$ dos respondentes ( $3^{\circ}$ quartil) disseram que o parceiro representa até $5 \%$ do faturamento da empresa, o que confirma o exposto anteriormente. Por fim, sub-setores como commodity, bazar e bebidas representam boa parcela de vendas, sendo que o setor de commodity tem grande representatividade, pois $75 \%$ ( $3^{\circ}$ quartil) dos representantes disseram que o varejo representa até $26,25 \%$ do faturamento total da empresa.

A pesquisa revelou também que o número de SKUs varia muito conforme o sub-setor. Os setores de commodity (com produtos vindos do sul) e o de eletroeletrônico (com produtos vindos do Norte) apresentam o menor número de SKUs. Já os setores de H\&L e Seca, que têm grande parcela no volume de vendas e com maior número de SKUs, estão mais próximos. Os fornecedores de capital não-nacional apresentam maior número de SKUs vendido para o parceiro varejista. Este fato pode ser justificado pelo maior faturamento, o que permite maior investimento no desenvolvimento de novos produtos. Logo pode representar a competitividade das empresas dentro de cada sub-setor, pois quanto maior o número de diferentes itens maior será a complexidade de distribuição dos produtos.

\subsubsection{Desempenho logístico}

A Tabela 5 mostra que $45,6 \%$ das entregas realizadas pelos fornecedores ocorre acima de duas vezes por semana (diárias ou até três vezes por semana). Dentro do grupo de mercearia, o setor de commodity é o que mantém maior frequiência de entregas de produtos durante a semana. Os produtos de maior giro (mercearia) têm maior freqüência quando comparados ao grupo de não-alimentos.

Tabela 5 - Dados de desempenho logístico por grupos setoriais

\begin{tabular}{|c|c|c|c|c|c|}
\hline \multirow[t]{2}{*}{ Grupo } & \multicolumn{2}{|c|}{ Freqüência de entrega } & \multicolumn{3}{|c|}{ Prazo de entrega } \\
\hline & $>2$ vezes na semana & $<2$ vezes na semana & Até 2 dias & 3 a 6 dias & Acima de 6 dias \\
\hline Mercearia & $36, \%$ & $38,4 \%$ & $45,6 \%$ & $23,2 \%$ & $5,6 \%$ \\
\hline Não-alimentos & $9,6 \%$ & $16,0 \%$ & $6,4 \%$ & $8,0 \%$ & $11,2 \%$ \\
\hline TOTAL & $45,6 \%$ & $54,4 \%$ & $52,0 \%$ & $31,2 \%$ & $16,8 \%$ \\
\hline
\end{tabular}

Observa-se que os prazos para entrega dos produtos após a colocação do pedido são, em média, 2 dias. No grupo de mercearia, os produtos de maior giro têm menor prazo de entrega, com exceção do setor de commodity, pois este representa empresas que, na sua maioria, são de outros estados (logo a distância dificulta a entrega no menor prazo). Já no grupo de não-alimentos, os setores eletro-eletrônico (cujos produtos vêm do Norte do país) e de bazar (alguns produtos de marca própria, cujos prazos de entrega incorporam também prazos de produção, pois esses produtos não são estocados) também têm prazos de entrega longos.

\subsubsection{Conhecimento do parceiro}

O conhecimento do parceiro pode ser representado pela freqüência de reuniões e pela ocorrência de visitas técnicas realizadas entre eles. 
A Tabela 6 mostra o quanto o fornecedor partilha desse conhecimento com a rede varejista de capital nacional e não-nacional.

Tabela 6 - Dados de conhecimento em relação ao parceiro varejista

\begin{tabular}{|c|c|c|c|c|}
\hline \multirow[t]{2}{*}{$\begin{array}{c}\text { Capital } \\
\text { do varejo }\end{array}$} & \multicolumn{2}{|c|}{$\begin{array}{l}\text { Freqüiência } \\
\text { de reuniões }\end{array}$} & \multicolumn{2}{|c|}{$\begin{array}{c}\text { Ocorrência } \\
\text { de visita técnica }\end{array}$} \\
\hline & Mensal & $\begin{array}{c}\text { Não- } \\
\text { mensal }\end{array}$ & Já teve & $\begin{array}{c}\text { Nunca } \\
\text { teve }\end{array}$ \\
\hline Nacional & $25,6 \%$ & $20,8 \%$ & $21,6 \%$ & $24,8 \%$ \\
\hline $\begin{array}{c}\text { Não- } \\
\text { nacional }\end{array}$ & $12,0 \%$ & $41,6 \%$ & $18,4 \%$ & $35,2 \%$ \\
\hline TOTAL & $37,6 \%$ & $62,4 \%$ & $40,0 \%$ & $60 \%$ \\
\hline
\end{tabular}

Observa-se que as reuniões mensais são mais freqüentes nas redes nacionais e, portanto, espera-se uma melhoria na resolução de contingências logísticas e menor número de devolução de produtos com esse parceiro.

O mesmo acontece com as visitas técnicas. No geral, ainda pouco se conhece da estrutura logística do parceiro. Essas visitas podem ser úteis para conhecer as estratégias do parceiro, a malha logística, a forma de armazenamento dos produtos e como são desenvolvidos acordos logísticos entre o parceiro e as empresas concorrentes (Vieira, Yoshizaki e Ho, 2009a).

\subsection{Relação entre colaboração e o desempenho logístico}

As empresas com relacionamento conflitante com a rede varejista têm menor desempenho logístico. No entanto, não se pode afirmar em todos os casos que a falta de colaboração tenha gerado isso. Em alguns casos, percebeu-se que problemas entre os fornecedores e as transportadoras, ou até mesmo problemas internos de produção foram os causadores do baixo desempenho logístico do fornecedor. Esses problemas se referem aos atrasos na programação de atendimento de pedido da rede e aos pedidos incompletos. Como forma de reduzir estes problemas, a rede varejista poderia compartilhar seus dados de estoque em troca do planejamento da produção e de reposição dos estoques do fornecedor. Logicamente, como essas variáveis são estratégicas para ambas as empresas, talvez pudesse haver melhor sinalização de ambas as partes em relação ao estudo conjunto de formas para melhor abastecimento dos produtos.

Segundo um entrevistado (varejo) “... essas multas não têm a intenção de punir ou cobrar do fornecedor uma quantia a mais. Elas existem para resguardar ruptura, por causa dos atrasos e falta de produtos...". Por outro lado, um gerente (fornecedor) diz: “... se estamos em uma reunião que se discute colaboração, não deveria existir este tipo de ação...". No entanto, segundo um dos entrevistados da rede varejista, desde a aplicação das multas, a ruptura do CD reduziu de $29 \%$ para $13 \%$ ao mês.

O compartilhamento de informações logísticas é fundamental para o bom desempenho logístico dos parceiros, principalmente para aquelas fornecedoras de commodity e eletroeletrônico que se encontram mais distantes da rede. Um exemplo disso é o envio de informação sobre as dimensões das embalagens (altura, largura e comprimento) para composição do palete pelo fornecedor. A partir desses dados, o varejo calcula (por meio de um programa computacional) o tamanho do palete e retorna para o fornecedor a informação de composição de carga. Essa troca de informação, além de atender às normas de padronização da rede varejista, o que implica em adequação ao cliente (um dos parâmetros avaliados no desempenho logístico), atende também ao fornecedor que tem melhor aproveitamento do palete e, conseqüentemente, melhor aproveitamento para composição da carga no veículo. Nesse sentido, o conhecimento do parceiro por meio de visitas técnicas e reuniões com os profissionais de logística podem ajudar no esclarecimento dos padrões de paletização, de estruturas utilizadas para armazenagem, de como é realizado o descarregamento, entre outros.

Outro problema de adequação de embalagens são os produtos cujas embalagens são fracionadas e colocadas em caixas ou contenedores. Este procedimento eleva o tempo de separação, movimentação e armazenamento dos produtos. O envolvimento das áreas funcionais das empresas (área operacional-varejo e a área de embalagens-fornecedor) seria interessante na busca de soluções para minimizar tais custos.

O programa colaborativo da rede varejista com os seus fornecedores apresenta vários pontos positivos. Segundo a equipe de varejo, houve uma padronização da linguagem e da comunicação entre as equipes de logística, o que contribuiu para melhor desenvolvimento de projetos conjuntos, facilitou o relacionamento estratégico com fornecedores e estimulou a equipe na busca de novos conhecimentos e desafios logísticos, como projetos (vendor managed inventory - VMI e cross-docking, entre outros). Isso permitiu maior desenvolvimento de novos processos logísticos e alinhamento entre as equipes de logística e de apoio, proporcionando um referencial entre os fornecedores e estimulando a eficiência destes.

Observou-se que, para atingir o melhor desempenho, os fornecedores incorreram em elevados custos logísticos e de transação. No entanto, segundo o fornecedor, esses investimentos são necessários para manter a sua competitividade no mercado. "Não questionamos tanto as regras impostas por esse varejo, pois aprendemos 
muito com as atualizações da área de logística... o que dificulta são as negociações com o comercial...", enfatizou um gerente (pequeno fornecedor).

Ressalta-se que, quando os pedidos são originários do Norte ou do Sul, os custos logísticos aumentam com a falta de colaboração, pois a devolução desses pedidos (por falta de ajudante, erro de nota fiscal, falta de agendamento, entre outros) gera baixos índices de desempenho logístico por não se adequarem às exigências da rede varejista. Segundo um coordenador (varejo) “... a distância aumenta o meu estoque de segurança. Se o serviço do concorrente é melhor, tenho que buscar novas alternativas para reduzir os meus custos com esses estoques...”. Esse fornecedor (commodity) tem aproximadamente 20 anos de relacionamento com a rede. Neste caso, o bom desempenho logístico independente do tempo de relacionamento, pois a rede varejista busca maior eficiência a um menor preço no mercado. Segundo um diretor (commodity) “... tenho 40 anos de relacionamento com a rede e, hoje, vejo que estou sendo engolido por grandes empresas do setor, pois estou sendo menos eficiente do que a concorrência, embora com mais tempo de atendimento à rede...”.

O Quadro 1 mostra uma comparação entre os principais elementos da relação e colaboração discutidos nesta seção.

\begin{tabular}{|c|c|c|}
\hline & Fornecedor & Varejo \\
\hline $\begin{array}{l}\text { Histórico de } \\
\text { relacionamento }\end{array}$ & $\begin{array}{l}\text { - O tempo de parceria é essencial para o } \\
\text { bom relacionamento. } \\
\text { - Há dificuldade de manter e de se adaptar às regras } \\
\text { do grande varejo. No entanto, se o relacionamento } \\
\text { torna conflitante, o desempenho logístico deixa de ser } \\
\text { preferencial para este cliente. }\end{array}$ & $\begin{array}{c}\text { - O histórico de relacionamento } \\
\text { apenas indica se as regras impostas estão } \\
\text { sendo cumpridas. } \\
\text { - As multas por atraso de entrega, por } \\
\text { exemplo, são uma forma de punição, } \\
\text { independentemente do histórico no passado. }\end{array}$ \\
\hline $\begin{array}{l}\text { Compartilhamento } \\
\text { de informações } \\
\text { logísticas }\end{array}$ & $\begin{array}{l}\text { - Há dificuldade para manter e aperfeiçoar as } \\
\text { informações operacionais com o varejo, mas para os } \\
\text { pequenos fornecedores a padronização nos processos } \\
\text { o qualifica para conquistar novos clientes e manter a } \\
\text { relação existente. }\end{array}$ & $\begin{array}{l}\text { - As visitas técnicas e uma maior freqüência } \\
\text { de reuniões logísticas permitem maior } \\
\text { conhecimento do parceiro para atuar nas } \\
\text { falhas e diminuir os custos operacionais } \\
\text { logísticos. }\end{array}$ \\
\hline $\begin{array}{l}\text { Envolvimento das } \\
\text { áreas funcionais }\end{array}$ & $\begin{array}{l}\text { - Permitem o desenvolvimento de novos projetos em } \\
\text { conjunto e abrem um contato para melhores } \\
\text { negociações, ajustes na parceria e facilita a } \\
\text { comunicação. }\end{array}$ & $\begin{array}{c}\text { - Uma melhor comunicação e padronização } \\
\text { dos processos logísticos ajudam na redução } \\
\text { dos custos logísticos. }\end{array}$ \\
\hline
\end{tabular}

Quadro1 - Comparação entre o fornecedor e o varejo em relação alguns elementos de colaboração

O Quadro 1 mostra que o tempo de relacionamento entre parceiros parece ser cada vez menos importante que outros elementos de colaboração, por exemplo, compartilhamento de informações e envolvimento entre as áreas funcionais e maior contato interpessoal entre as partes. Atuar nesses elementos ajuda no melhor desempenho logístico no que tange frequiência no abastecimento e menor prazo de entrega dos produtos. O compartilhamento de informações logísticas do varejista com o grande fornecedor é importante para a redução dos custos logísticos. Isso se deve ao melhor entendimento da complexidade das operações logísticas no atendimento a diversos outros tipos de clientes como, por exemplo, atacadistas e redes de médio varejo. Já o compartilhamento de tais informações com o pequeno fornecedor é importante para reduzir custos logísticos por meio da padronização de processos dedicados. $\mathrm{O}$ envolvimento entre as áreas funcionais dentro de cada empresa e entre as das empresas parceiras é fundamental para troca de informações operacionais e estratégicas. Foram observados casos em que o entendimento entre áreas afins de empresas parceiras é mais harmonioso do que entre áreas da mesma empresa.

\subsubsection{O efeito da colaboração no desempenho logístico dos grandes fornecedores}

A análise das respostas dos representantes dos fornecedores, principalmente aqueles de maior faturamento, mostrou que a colaboração produz um maior efeito no desempenho logístico. Uma explicação plausível poderia ser conforme segue. Primeiro, tais empresas são mais organizadas em termos de estrutura logística (frota, equipe e softwares) e, mesmo se distantes, conseguem atender aos acordos colaborativos (ou seja, ao realizarem um acordo colaborativo com uma grande rede de varejo elas contam com uma infra-estrutura para sua melhor operacionalização). Geralmente, essas grandes empresas fazem promoções freqüientes, o que provoca a "desova" de seus produtos nas grandes redes varejistas, ainda que estas, tipicamente, representem apenas $10 \%$ do seu faturamento. Como tais empresas mantêm entregas mais freqüentes, isso tem menor impacto no desbalanceamento de estoques nas grandes redes de varejo. Logo, as grandes empresas têm condições de atender, de forma mais eficiente, às exigências das grandes redes. Segundo, por questões estratégicas, 
o volume de vendas para as grandes redes varejistas garante maior faturamento e, ao mesmo tempo, o alto fluxo de produtos e quantidades de SKUs transacionados faz com que as entregas sejam gerenciadas com mais cuidado. Esse gerenciamento é facilitado pelo compartilhamento de informações logísticas e comerciais (como dados sobre previsão de demanda no ponto de venda e sobre estoques), pelas ações conjuntas das equipes de logística das duas empresas (por meio de reuniões, projetos e contato via meios eletrônicos) e por um contato direto que permite atender às contingências logísticas que venham a surgir durante o abastecimento.

\subsubsection{O efeito da colaboração no desempenho logístico quanto ao volume de vendas dos fornecedores}

Outro fator observado é a melhora que os elementos de integração interpessoal (confiança, reciprocidade, interdependência e flexibilidade) produzem do desempenho logístico quando o volume de vendas para o varejo aumenta. $\mathrm{O}$ fornecimento de um volume maior em situações especiais, como entregas em período de demanda alta, exige ações rápidas e variadas. Isso leva as empresas a uma relação de interdependência cuja base é estabelecida em torno da confiança, reciprocidade e flexibilidade em atender às urgências do parceiro, relação essa que, talvez, tenha mais importância do que outras dentro da colaboração (por exemplo, compartilhamento de custos e ganhos logísticos).

É claro que há uma maior predisposição para atendimento diferenciado à grande rede. Para o fornecedor, elas são clientes estratégicos, o principal canal de divulgação dos seus produtos e os termos de colaboração são bem conhecidos, principalmente devido às usuais reuniões periódicas.

\subsubsection{O efeito da colaboração no desempenho logístico dos fornecedores com maior frequência de entrega}

A pesquisa também mostrou que a alta freqüência de entrega exige dos fornecedores maior precisão no cumprimento dos prazos e, portanto, a garantia de um bom desempenho logístico (em especial em períodos de demanda alta e urgente e com entregas mais freqüentes) depende de um grande empenho na colaboração entre os parceiros. Além disso, o atraso ou falha na entrega de produtos e o descumprimento de agenda de entrega (que provoca ociosidade da doca) podem gerar multas maiores do que quando a freqüência é baixa. Maior freqüência de entrega significa maior contato entre as empresas e, conseqüentemente, melhor troca de informações. A Figura 2 resume a relação entre colaboração e desempenho logístico.

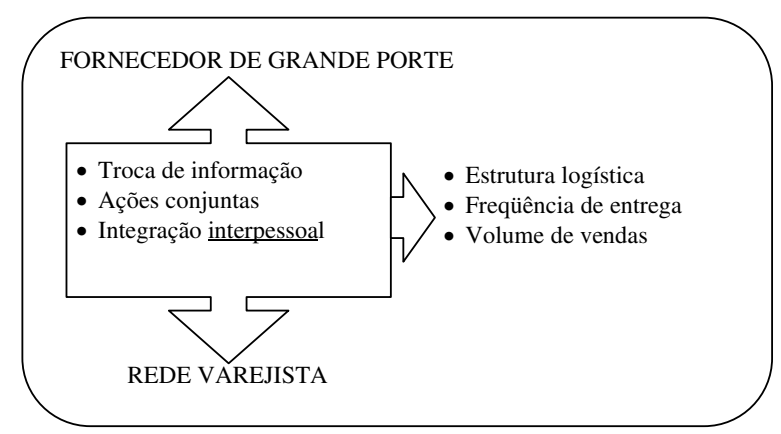

Figura 2 - Colaboração e desempenho logístico entre parceiros de grande porte.

A Figura 2 resume como a colaboração se dá, em maior grau, entre parceiros de grande porte. De um lado (seta acima) os fornecedores que possuem uma maior estrutura logística para distribuição de seus produtos, os quais atendem à rede varejista com maior freqüência de entrega e têm condições de fornecer maior volume de produtos. Do outro lado as grandes redes varejistas (seta abaixo) que são seus clientes estratégicos. Esses fornecedores apresentam maior desempenho logístico e têm um canal de comunicação aberto com a rede varejista, baseado na constante troca de informações e em ações conjuntas, além de manter uma integração interpessoal efetiva por meio de reuniões periódicas. $\mathrm{O}$ aumento dessa colaboração proporciona um melhor desempenho logístico do fornecedor.

\subsection{Relação entre colaboração e os custos de transação}

Observou-se que, na maioria das vezes, os custos de transação são decorrentes da falta de compartilhamento de informações logísticas e do pouco envolvimento das áreas funcionais dos parceiros. Como exemplos têmse: pedidos de mudança de parâmetros logísticos que não são atendidos no tempo esperado, cancelamentos de pedidos não atendidos a tempo, entregas fora dos parâmetros logísticos (palete fora das dimensões especificadas). Segundo um gerente (grande fornecedor) “... quando um pedido é montado nas condições que a rede varejista pede, tenho que colocar pessoas treinadas para trabalhar neste pedido. Se este pedido é cancelado tenho, além dos custos logísticos (de retrabalho da carga e frete de retorno), perda de tempo na realocação de recursos (máquinas, equipamentos $e$ pessoas) e desestímulo da equipe operacional no atendimento de um novo pedido desse cliente...”. Logo, um erro de parâmetro de paletização pode gerar custos logísticos (devoluções, frete de retorno, multas, entre outros) e custos de transação (reuniões para alinhamento de informação, adequação aos novos parâmetros, entre outros). Além disso, à medida que aumenta o número de itens (SKUs), os problemas com a parametrização também aumentam, ou seja, os custos de monitoramento da transação se elevam. 
Percebe-se que, na colaboração, há um esforço de compartilhamento de informações logísticas e interação das áreas funcionais das empresas para reduzir custos de transação. Por exemplo, o acompanhamento da colocação de pedidos e verificação de parâmetros logísticos, que embora tenham custos ex-ante (contratação de transportadoras dedicadas, acerto de informações e monitoramento da transação) têm o objetivo de reduzir custos ex-post (multas, ruptura de gôndola e retrabalho com cargas devolvidas).

Embora o tempo despendido pela alta gerência em reuniões gere maiores custos de transação ex-ante, estes custos podem ser compensados no futuro, pois novos acordos podem surgir e problemas logísticos podem ser resolvidos com maior agilidade. Portanto, o monitoramento das transações e reuniões entre coordenadores e gerentes deve ser freqüente no sentido de evitar o aumento de custos ex-post (conflitos, realinhamento das áreas funcionais e perda de contato).

A colaboração também faz com que custos de transação associados a custos logísticos sejam reduzidos em ambas as empresas. Por exemplo, há casos em que o fornecedor entrega produtos fora do padrão de qualidade exigido pela rede ou com problemas na embalagem. Se houver ações conjuntas entre as áreas, problemas futuros (como devolução, custos com movimentação e armazenagem desnecessários) podem ser evitados. Segundo um analista (varejo) “... esse fornecedor ( empresa de grande porte) trocou o padrão de paletização e não nos informou. Agora estão ocorrendo devoluções de carretas ...".

Os custos de transação também são menores quando há maior integração interpessoal. Segundo um analista (varejo) “... as minhas reuniões com esse fornecedor são tranqüilas, pois nós estamos diariamente em contato. Com isso, embora tenha um monitoramento, os problemas são menores e resolvidos mais rapidamente, menos conflito. $O$ difícil é você alinhar as coisas, mas depois é mais ágil...”. Essa maior reciprocidade, flexibilidade, confiança, comprometimento e interdependência na relação faz com que os custos de adequação da transação sejam menores, pois os contratos já são conhecidos e os processos já estão alinhados. Segundo o mesmo analista (varejo) “... essa constante troca de informação tem contribuído para maior aproximação de outras áreas das duas empresas e tem melhorado o desempenho logístico do fornecedor e gerado menos retrabalho nas operações diárias...”.

O Quadro 2 mostra uma comparação da relação entre os principais elementos de colaboração e custos de transação discutidos nesta seção para o varejo e o fornecedor.

\begin{tabular}{|c|c|c|}
\hline & Fornecedor & Varejo \\
\hline Retrabalho & $\begin{array}{c}\text { São constantes as novas exigências } \\
\text { nas operações logísticas requisitadas } \\
\text { pelo varejo, o que onera os custos de } \\
\text { transação e logísticos. }\end{array}$ & $\begin{array}{c}\text { Por se tratar de muitos itens, vários problemas } \\
\text { na padronização dos parâmetros logísticos são } \\
\text { freqüentes. }\end{array}$ \\
\hline $\begin{array}{l}\text { Alinhamento } \\
\text { das áreas } \\
\text { funcionais }\end{array}$ & $\begin{array}{l}\text { A presença da alta gerencia é importante para } \\
\text { firmar novos acordos e realinhar as estratégias } \\
\text { com o varejista. }\end{array}$ & $\begin{array}{l}\text { Nem sempre há uma troca de informação } \\
\text { substanciada nas necessidades logísticas entre o } \\
\text { comercial e a logística }\end{array}$ \\
\hline $\begin{array}{l}\text { Elementos } \\
\text { de integração } \\
\text { interpessoal }\end{array}$ & $\begin{array}{l}\text { Quando há mudança na equipe que atende a rede } \\
\text { varejista, os custos de transação ex-post tendem } \\
\text { a ser maiores. }\end{array}$ & $\begin{array}{l}\text { O contato diário entre os responsáveis de } \\
\text { logística das empresas contribui para a } \\
\text { diminuiçãa dos custos ex-post. }\end{array}$ \\
\hline
\end{tabular}

Quadro 2 - Comparação entre fornecedor e varejo para colaboração e custos de transação

O Quadro 2 mostra que os retrabalhos são desencadeados pela rede varejista que, ora tem que se adequar ao cadastro de diferentes tipos de produtos, ora faz exigências para adequação aos padrões existentes da rede. $\mathrm{O}$ alinhamento das áreas funcionais homônimas dos parceiros parece garantir novos projetos, porém isto acontece com maior eficiência se as áreas internas de cada parceiro estiverem em sintonia. O convívio diário faz com que as partes estejam em constante e intensa troca de informações, promovendo maior entendimento e harmonia que se traduz em agilidade no atendimento às solicitações de lado a lado. Como corolário, a ocor- rência de mudanças na equipe pode gerar custos extras com treinamento, re-entrosamento e novos realinhamentos dos processos logísticos.

\subsubsection{O efeito da colaboração na incerteza das negociações}

A incerteza, presente em elementos como renegociação de contratos, tempo para resolução de contingências logísticas e para negociação de novos acordos logísticos, está associada ao ambiente de colaboração. Foi observado que o aumento da colaboração interpessoal 
diminui as incertezas na relação. Isso pode ser explicado pelo constante envolvimento dos parceiros na resolução de contingências logísticas (atraso de entrega e devolução de produtos, entre outros) e pelo contato direto nas negociações de contrato e efetivação de novos acordos logísticos.

\subsection{2 $O$ efeito da colaboração na especificidade de ativo}

Os resultados mostraram que a colaboração está associada a uma maior especificidade de ativo, logo pode implicar um aumento dos custos de transação. Ou seja, a colaboração faz com que as empresas invistam em serviços e produtos direcionados para determinados clientes varejistas (por exemplo, entrega e equipe dedicada, embalagens especiais) criando, assim, um risco de perda do investimento numa eventual interrupção da parceria (custo ex-post). No entanto, esse custo pode ser compensado pelo aumento do volume de vendas, pelo comprometimento entre as partes (redução do risco de ruptura da parceria) e pela facilidade em se adequar às exigências dos clientes varejistas. Espera-se, portanto, que as grandes empresas tenham maior potencial para realizar esses investimentos, pois têm melhor estrutura organizacional e maior competitividade de mercado (relação preço versus volume) quando comparado às demais. Nesse sentido, o aumento da colaboração faz com que essas grandes empresas elevem os investimentos em ativos específicos.

Por outro lado, o aumento de investimento em ativo específico nem sempre significa aumento dos custos de transação. Como ressaltou Dyer (1997), o aumento do compartilhamento de informação permite reduzir os custos de transação e aumentar o investimento em ativos específicos. Isso porque a constante troca de informação e o contato mais próximo entre os agentes, por meio de ações conjuntas e troca de informação estratégica (participação da alta gerência na definição dos acordos logísticos e conhecimento da realidade logística dos parceiros) dificultam a entrada de outros participantes para atendimento desse canal. Essa troca de informação e o contato funcionam como salvaguardas no sentido de evitar ações oportunistas da rede varejista (por exemplo, forçar redução de margem de lucro mediante ameaça de troca de fornecedor). Logo, esses são investimentos que podem compensar custos extras de busca de informação desnecessária (como constantes renegociações), treinamento de diferentes equipes e em diferentes horizontes de tempo.

Verificou-se também que o efeito da colaboração no investimento em ativos específicos difere para o tipo de varejo (nacional e não-nacional). A pesquisa mostrou, por meio de uma análise de frequiência, que existe compartilhamento de custos e ganhos logísticos em relação aos investimentos em ativos específicos entre os fornecedores e o varejo de capital nacional. Isso talvez se deva a três fatores: (1) maior frequência de reuniões logísticas entre as partes, o que facilita a divisão de trabalho e troca de informações com o objetivo de reduzir custos operacionais, por exemplo, agendamento específico para entrega; (2) maior ocorrência de visitas técnicas, o que contribui para o melhor entendimento das operações logísticas, por exemplo, melhores formas de armazenamento dos produtos (quantidade de caixas empilhadas, locais e cuidados no transporte); (3) necessidade de adequação de alguns fornecedores, principalmente os de menor porte, às exigências da rede, pois esta pode representar o seu principal canal de distribuição, como, por exemplo, as empresas que fornecem produtos de marca própria para esse varejo. Por outro lado, de acordo com os respondentes, há um grau maior de exigência para atendimento de normas logísticas (horários de entrega, lacres, documentos recebidos previamente via EDI, entre outras) da grande rede nacional em relação à rede não-nacional. Tais exigências podem até superar o grau de cooperação e tornar a parceria menos interessante para o fornecedor, por onerar os seus custos além daqueles já previstos na transação.

\subsubsection{Assimetrias de informação entre a rede varejista e os fornecedores}

Embora paguem uma taxa para transmitir as notas fiscais via EDI, alguns fornecedores não sabem que essa ferramenta pode dar acesso a informações sobre os inventários e vendas da rede varejista. Logo, os fornecedores pagam pela integração, mas não usufruem de todos os benefícios dela. Segundo um entrevistado (fornecedor) "... não há nenhuma instrução ou motivação para que utilizássemos isso...”. Essa assimetria de informação relativa a estoques e timing de vendas pode deixar o fornecedor em desvantagem e protege o varejista contra possíveis ações oportunistas.

Uma das maiores reclamações dos fornecedores é a falta de empenho na comunicação. Segundo um entrevistado (fornecedor) “... percebemos que há uma pré-disposição das pessoas em melhorar o relacionamento, mas muitas informações não são atualizadas e somos cobrados por erros nos atrasos de informação...”. Evidentemente a assimetria de informação que essa falta de empenho traz é um claro risco moral para o fornecedor.

O problema no tratamento das multas também gera assimetrias de informação que, novamente, parece ocorrer em função de risco moral. Relata uma analista (varejo), “... a multa é automática e depois se o fornecedor reclama, nós analisamos caso a caso...”. Segundo um funcionário (fornecedor), em várias notificações de multas os motivos não estão explicitados: “... contratamos 
uma pessoa exclusiva para tratar as multas (motivo, data e como reduzir os erros)...". Um relato típico de vários entrevistados (fornecedores) é: “... a ocorrência nem sempre está correta. Isso gera um re-trabalho na operação, pois os motivos são desconhecidos ou pouco explicados...".

A Figura 3 resume o que foi apresentado na relação colaboração e custos de transação.

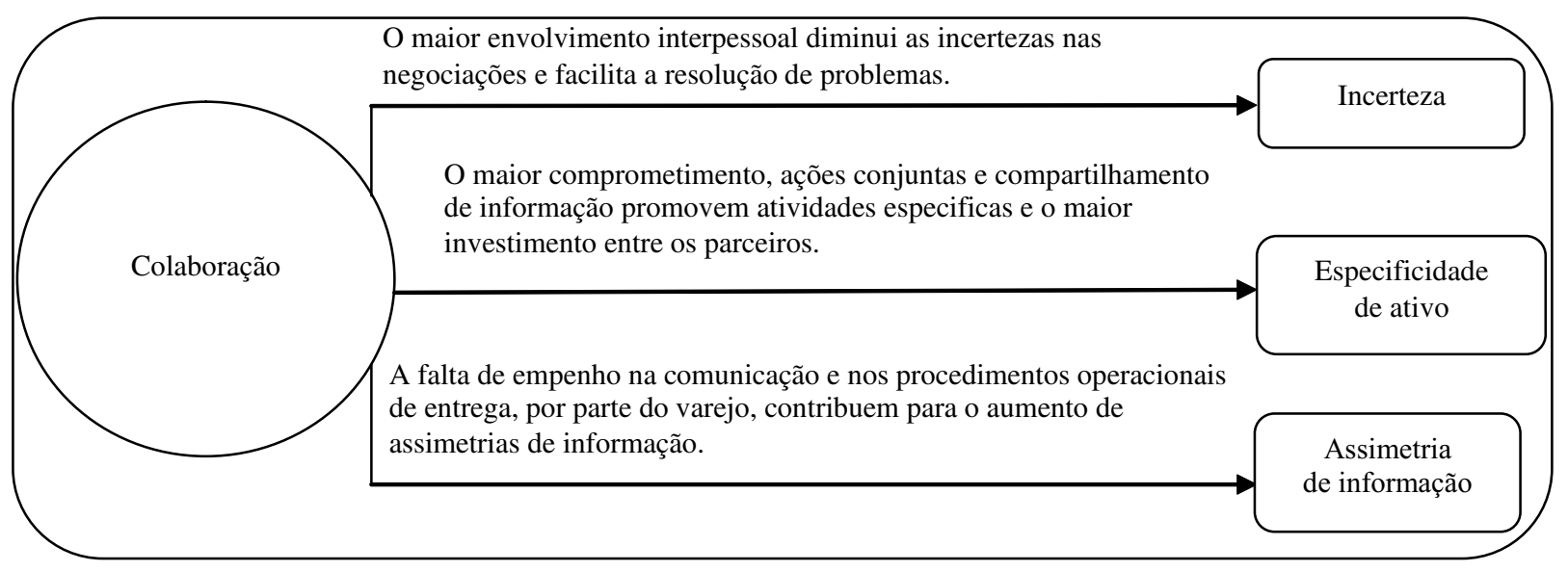

Figura 3 - Relações entre colaboração e os elementos de custos de transação.

\section{Considerações finais}

Observou-se que a colaboração pode ser estudada numa estrutura de análise da transação fornecedorrede varejista, principalmente quando de um lado se encontram fornecedores de bens de consumo duráveis e não-duráveis de grande porte, alguns destes localizados distantes do local de entrega (centro de distribuição da rede varejista). Percebeu-se que essa colaboração contribui mais acentuadamente para a melhoria do desempenho logístico quando os fornecedores são de grande porte. Com fornecimento mais dedicado, dispõem de um maior volume de produtos e atendem à rede varejista com maior frequiência e menor prazo de atendimento de pedido.

A pesquisa indicou que a falta (ou falhas) de colaboração entre os parceiros tem gerado inúmeras ineficiências logísticas e, conseqüentemente, aumentos dos custos logísticos e aumento significativo dos custos de transação, incluindo o que tange às assimetrias de informação e incertezas nas negociações. Isso indica que com confiança, flexibilidade nas transações logísticas, troca efetiva de informações e fortes relações de interdependência e de reciprocidade, a parceria pode conseguir menor custo logístico, maior volume de vendas e maior comprometimento na relação, como acontece com grande parte dos fornecedores nacionais.

Certamente relacionamentos mais estreitos (com alto grau de interdependência) implicam em mais investimento em ativos específicos, aumentando os custos ex-post de transação. Contudo, com maior freqüência de contratação e volume negociado, acredita-se que, no longo prazo, os custos de transação podem se reduzir. Isso traz implicações para as estratégias de relacionamento comercial.

Todos esses resultados concordam com os encontrados na literatura, mas o estudo não apenas mostrou como ocorrem num contexto importante e freqüente, mas também revelou alguns pormenores interessantes.

O estudo registrou depoimentos de profissionais de logística que relataram suas experiências de parcerias de longo tempo. Esses depoimentos revelaram detalhes interessantes como, por exemplo, que o tempo de relacionamento da parceria não é mandatório para que se tenha colaboração eficaz. Muitas pesquisas evidenciam a importância do tempo de parceria; porém, isso nem sempre é a única ou a principal variável a ser analisada num relacionamento fechado.

Pode-se concluir ainda que, sob o "discurso" da colaboração, o grande varejo impõe regras aos pequenos e médios fornecedores. Ele tem consciência de sua importância como canal de venda para o fornecedor, não por ser um grande cliente, mas por atingir diretamente uma imensa variedade de consumidores em muitas partes do território nacional.

A pesquisa não mostra uma análise quantitativa dos resultados, o que contribuiria para maior confiança na generalização empírica. Além disso, a análise é feita a partir de depoimentos, entrevistas e observações de maneira não estruturada. No entanto, o estudo de caso é relevante por considerar um período de observação longo, intenso e detalhado de transações, permitindo 
uma visão contextualizada. Uma análise mais profunda poderia ser realizada entre parceiros em diferentes momentos da transação. Assim, poderiam ser analisados acordos logísticos, cláusulas contratuais e acompanhadas diferentes formas operacionais de elaboração e abastecimento de pedidos.

Como sugestão para trabalhos futuros se destaca, também, a análise de grupos dedicados aos projetos logísticos, em que a saída de membros-chave da equipe contribui para a ruptura da continuidade do projeto com o parceiro.

Os autores agradecem a CAPES, pelo financiamento parcial desta pesquisa.

\section{Referências}

ANDERSON, J. C.; HAKANSSON, H.; JOHANSON, J. Dyadic business relationships within business network context, Journal of Marketing, Vol. 58, number 4, pp.1-15, 1994.

ANDERSON, J. C.; NARUS, J. A. A model of distributor firm and manufacturer firm working partnerships. Journal of Marketing, Vol.54, pp.42-58, 1990.

BARRATT, M. Understanding the meaning of collaboration in the supply chain, Supply Chain Management: An International Journal, Vol. 9 Number 1, pp. 30-42, 2004.

BATT, P. J. Examing the performance of the supply chain for the potatoes in the red river Delta using pluralistic approach, Supply Chain Management: An International Journal, Vol. 8, number 5, pp. 442-454, 2003.

BOWERSOX, D. J. The strategic benefits of logistics alliances, Harvard Business Review, Vol. 68, number 4, pp. 36-43, 1990.

CANNON, J. P.; HOMBURG, C. Buyer-supplier relationships and customer firm costs, Journal of Marketing, Vol. 65, number 1, pp. 29-43, 2001.

CLARO, D. P.; CLARO, P. B. O.; ZYLBERSZTAJN, D. The value of downstream information: exploring the effects of business networks on buyer-supplier relationships. American Marketing Association, Summer, pp.210-218, 2005.

COLlins, A.; HENCHION, M.; O'REILLY, P. Logistics customer service: performance of irish food exporters, International Journal of Retail \& Distribution Management, Vol. 29, number 1, pp. 6-15, 2001.
CONCEICAO, S.V.; QUINTAO, R.T. Avaliação do desempenho logístico na cadeia brasileira de refrigerantes. Revista Gestão \& Produção, São Carlos, SP, v. 11, n. 3, p. 441-453, set-dez 2004.

CORBETT, C. J.; BLACKBURN, J. D.; WASSENHOVE, L. N. V. Case study partnerships to improve supply chains, Sloan Management Review, Vol. 40, number 4, pp. 71-82, 1999.

COYLE, J. J.; BARDI, E. J.; LANGLEY, C. J. Jr. The Management of Business Logistics: A Supply Chain Perspective, 7 th, Ohio: Thompson Learning, 2003, 707 p. 2003.

DAUGHERTY, P. J.; ELLINGER, A.E.; GUSTIN, C. M. Integrated logistics: achieving logistics performance improvements, Supply Chain Management, Vol. 1, number 3, pp. 25-33, 1996.

DAY, G. S. Advantages Alliances, Journal of Academy of Marketing Science Review, Vol. 23, number 4, pp.297-300, 1995.

DYER, J. H. Does governance matter? Keiretsu alliances and asset specificity as sources of japanese competitive advantage, Organization Science, Vol. 7, number 6, pp. 649-666, 1996.

DYER, J. H. Effective interfirm collaboration: how firms minimize transaction costs and maximize transaction value, Strategic Management Journal, Vol. 18, number 7, pp. 535-556, 1997.

EISENHARDT, K; SCHOONHOVEN, C. B. Strategic alliance formation in entrepreneurial firms: strategic needs and social opportunities for co-operation, Organizational Science, Vol. 7, pp. 136-150, 1996.

ELLRAM, L. M. International supply chain management: strategic implications for the purchasing function, Dissertation presented in partial fulfilment of the requirements for the degree of Doctor of Philosophy in the Graduate School of the Ohio State University, 1990. 343 p.

EVANS, P.; WOLF, B. Regras da colaboração. Harvard Business Review, Jul, pp. 46-54, 2005.

FRANKEL, R.; GOLDSBY, A. B.; WHIPPLE, J. M. Grocery industry collaboration in the wake of ECR. International Journal of Logistics Management. Vol 13, number 1, pp. 57-72, 2002.

GANESAN, S. Determinants of long-term orientation in buyer-seller relationships, Journal of Marketing, 
Vol. 58, number 2, april, pp-1-19, 1994.

GHOSHAL. H, S.; MORAN, P. Bad for practice: a critique of the transaction cost theory. Academy of Management Review, Vol. 21, number 1, pp.13-47, 1996.

GRAY, B.; WOOD, J. Collaborative alliances: moving from practice to theory. Journal of Applied Behavioral Science. V. 27, pp. 139-162, 1991.

GRIESINGER, D. W. The human side of economic organization. Academy of Management Review, Vol. 15, number 3, pp.478-499, 1990.

GROVES, G.; VALSAMAKIS, V. Supplier-customer relationships and company performance, International Journal of Logistics Management, Vol. 9, number 2, pp. 51-63, 1998.

HARGROVE, R. Colaboração criativa: a interação de talento e diversidade para obter resultados positivos. São Paulo: Editora Cultrix, 1998. 240 p.

HEIDE, J. B.; JOHN, G. Alliances in industrial purchasing: the determinants of joint action in buyer supplier relationships. Journal of Marketing Research, Vol. 27, number 1, feb, pp.24-36, 1990.

HEIDE, J. B.; JOHN, G. Do norms matter in marketing relationships? Journal of Marketing, Vol.56, number 2, Apr, pp.32-44, 1992.

HEIDE, J. B.; MINER, A. S. The shadow of the future: effects of anticipated and frequency of contract on buyer-seller cooperation. Academy of Management Journal, Vol.35, number 2, p. 27, 1992.

IRELAND, R.; BRUCE, R. CPFR: only the beginning of collaboration. Supply Chain Management Review, pp. 80-88, 2000.

HOBBS, J.E. A transaction cost approach to supply chain management. Supply Chain Management. Vol. 1, No. 2, pp. 15-27, 1996.

JAP, S. D,; GANESAN, S. Control mechanisms and the relationship life cycle: implications for safeguarding specific investments and developing commitment, Journal of Marketing Research, Vol. 37, may, pp.227245,2000

JONES, C.; HESTERLY, W. S.; BORGATTI, S. P. A general theory of network governance: exchange conditions and social mechanisms. Academy of Management Review, Vol. 42, number 4, pp.911-945, 1997.
KLEIN, B.; CRAWFORD, R.; ALCHIAN, A. Vertical Integration, Appropriable Rents, and the Competitive Contracting Process. Journal of Law and Economics, Chicago, v. 21, n. 2, 1978.

KOGUT, B. The stability of joint ventures, Journal of Industrial Economics, Vol 38, pp.1-16, 1989.

KUMAR, $N$. The power of trust in manufacturer-retailer relationship, Harvard Business Review, nov-dec, pp. 92-106, 1996.

KUMAR, N.; SCHEER, L. K.; STEENKAMP, J. E. M. Interdependence, punitive capability, and the reciprocation of punitive actions in channel relationships, Journal of Marketing Research, Vol. 35, may, pp. 225235, 1998.

KNOW, I., G.; SUH, T. Factors affecting the level of trust and commitment in supply chain relationships, Journal of Supply Chain Management, Vol. 40, number 2, pp. 4-11, 2004.

LAMBERT, D. M. Developing a customer-focused logistics strategy, International Journal of Physical Distribution and Logistics Management, Vol.23, number 6, pp. 12-19, 1993.

LANGLOIS, R. N. Transaction Cost Economics in Real Time. Industrial and Corporate Change. Vol 1, n.1, 1992.

LAZZARINI, S.G. Estudos de caso: aplicabilidade e limitações do método para fins de pesquisa. Economia \& Empresa, Universidade Mackenzie, Vol. 2, n.4, 1995.

LEE, H. L.; PADMANABHAN, V. WHANG, S. Information distortion in a supply chain: the bullwhip effect. Management Science, Vol 43, No 4, pp. 546-558, 1997.

MACNEIL, I. R. Contracts: adjustment of long-term economic relations under classical, neoclassical, and relational contract law. Northwestern University Law Review, Vol.76 number 6, pp.854-905, 1978.

MOBERG, C. R.; SPEH, T. W. Evaluating the relationship between questionable business practices and the strength of supply chain relationships, Journal of Business Logistics, Vol. 24, number 2, pp. 1-19, 2003.

MORGAN, R. M.; HUNT, S. D. The commitment - trust theory of relationship marketing. Journal of Marketing, Vol.58, number 3, jul, pp.20-38, 1994. 
MOHR, J., SPEKMAN, R. Characteristics of partnership success: partnership attributes, communication behavior, and conflict resolution techniques. Strategic Management Journal, Vol.15, number 2, pp.135$152,1994$.

NESHEIM, T. Externalization of the core: antecedents of collaborative relationships in clothing supply chains, European Journal of Purchasing and Supply Management, Vol. 7, pp. 217-225, 2001.

PARKHE, A. Building trust in international alliances. Journal of World Business, Vol. 33, number 4, pp.417437, 1998.

PFEFFER, J.; SALANCIK, G.R. The external control of organizations: A resource dependence perspective. New York: Harper and Row, 1978.

PIGATTO, G.; ALCANTARA, R. L. C. Relacionamento colaborativo no canal de distribuição: uma matriz de análise. Gestão e Produção, Vol.. 14, p. 167-177, 2007.

RINDFLEISCH, A.; HEIDE, J. B. Transaction costs analysis: past, present and future applications, Journal of Marketing, Vol. 61, number 4, pp.20-54, 1997.

SAUVAGE, T. The relationship between technology and logistics third-party providers. International Journal of Physical Distribution \& Logistics Management. Vol. 33, number 3, pp. 236-253, 2003.

SIMATUPANG, T. M.; SRIDHARAN, R. The collaborative supply chain, International Journal of Logistics Management, Vol. 3, Number 1, pp. 15-30, 2002.

SIMATUPANG, T. M.; SRIDHARAN, R. The collaboration index: a measure for supply chain collaboration. International Journal of Physical Distribution \& Logistics Management. Vol. 35, number 1, pp. 44-62, 2005.

STANK, T. P.; KELLER, S. B.; DAUGHERTY, P. J. Supply chain collaboration and logistical service performance, Journal of Business Logistics, Vol. 22, pp.29-48, 2001.

VIEIRA, J. G. V.; YOSHIZAKI, H. T. Y. ; DIAS, D. F. Estudo da relação entre colaboração e custos logísticos e de transação na cadeia de suprimento do varejo. In: XXVII Encontro Nacional de Engenharia de Produção, 2007, Foz do Iguaçu/PR. A Energia que move a produção: um diálogo sobre integração, projeto e sustentabilidade, 2007.

VIEIRA, J. G. V.; COUTINHO, D. P. Avaliação da Colaboração Logística entre uma Distribuidora e seus Fornecedores. Revista Eletrônica Produção e Enge- nharia, v. 1, p. 53-68, 2008. Disponível em http://www. revistaproducaoengenharia.org/artigos/109_53.pdf.

VIEIRA, J. G. V; MACHADO, V. R. Colaboração logística: um estudo entre supermercados de pequeno e médio porte e seus fornecedores. GEPROS - Gestão da Produção, Operações e Sistemas, ano 3, n. 2, p. 89103, Abr-Jun, 2008.

VIEIRA, J.G.V.; YOSHIZAKI, H.T.Y.; LEE L.H. Collaboration intensity in the Brazilian supermarket retail chain. Supply Chain Management: An International Journal. v. 14, n. 1, January, pp.11-21, 2009a.

VIEIRA, J., YOSHIZAKI, H. T. Y.; HO, L. L. Um estudo sobre colaboração logística entre fornecedor de bens de consumo e redes de varejo supermercadista. Gestão e Produção, Dez, vol.16, no.4, p.556-570. 2009b.

VIEIRA, J. G. V.; YOSHIZAKI, H. T. Y.; LUSTOSA, L. J. Um estudo exploratório sobre colaboração logística num grande varejo supermercadista. Produção. v. 20, n. 1 , p. $135-147.2010$.

VON NEUMANN, J. \& MORGENSTERN, O. Theory of Games and Economic Behavior. Princeton University Press, 1972.

WILLIAMSON, O.E. The Economic Institutions of Capitalism. New York: The Free Press, 1985. 450 p.

ZANQUETTO, H. F.; FEARNE, A.; PIZZOLATO, N. D. The measurement of benefits from and enablers for supply chain partnerships in the UK fresh produce industry, Chain and network science, pp. 59-74, 2003.

YIN, R. K. Case study research:design and methods. Sage, Newbury PARK, 1989. 166 p. 

Editoração e impressão:



DA UNIVERSIDADE FEDERAL DO RIO GRANDE DO SUL 